\title{
ELEMENTOS PARA UMA ESTÉTICA ENGAJADA: A FUNÇÃO SOCIAL DA ARTE
}

\section{Aspects for a engaged Aesthetics: on the social function of arts}

\section{João Batista Magalhães Prates - UNIFESP/Brasil}

RESUMO: O presente texto trata do esboço de uma nova proposta de teoria literária (e artística em geral), que propõe uma axiomática para a prática artística, que congregue todos os praticantes da escrita, todos os artistas, no trabalho conjunto da construção da utopia, realizando a libertação humana plena pelo espírito, enquanto essa possibilidade está vedada ao acesso material, preparando-nos para o seu acesso, num futuro sempre por vir, por construir, cultural e materialmente. Baseamo-nos na teoria bergsoniana para esboçar uma proposta de normatização do bom e do belo, vinculada às suas reflexões morais. Aqui a "boa" arte se delineia sob outro ponto de vista, recuperada da descrença relativista da modernidade, que desmascarou os mecanismos ideológicos nela contidos até então. Feita a redução ao absoluto, cabe voltarmos ao movimento inverso da construção, à luz das descobertas recentes, para que fujamos da subjetividade pura em sua tentativa de definição.

Palavras-chave: Estética. Metafísica. Política. Subjetividade.

ABSTRACT: The present paper is a draft of literary theory (and artistic theory, in general), wich proposes an axiomatic for the art practice that gathers all the comunnity of writers, all engaged in any form of art, in the joint work of constructing the utopia, making possible the complete human libertation through the mind, while this possibility is sealed to our material acess, but preparing us to it, in an ever future, an ever needing to built future, by both cultural and material means. Built around bergsonism moral philosophy, we try to outline a normative proposal for the good and the beautiful. Here "good" art is defined by another point of view, departing from the classical aproaches, in an attempt to recover this Idea from the relativistic tornado that floodded modernity, exposing ideological mecanisms that the same ideas once masked. Made the absolute reduction, it is time to built back a new definition of good art, in the light of the recent discoveries, so that we can refuse the purê subjectivity when trying to define it.

Keywords: Aesthetics. Metaphysics. Politics. Subjectivity

\section{INTRODUÇÃO}

Não há fronteiras nesta luta de morte, nem vamos permanecer indiferentes perante o que aconteça em qualquer parte do mundo. A vitória nossa ou a derrota de qualquer nação do mundo, é a derrota de todos (Che Guevara).

No filme “As Palavras” (Brian Klugman e Lee Sternthal, 2012) é narrada uma história que, penso, serve bem para ilustrar o problema que proponho para reflexão neste trabalho, a 
saber, o da relação entre ética, política e estética. Nossa hipótese, elaborada tendo por base a obra de Henri Bergson que desvenda a partir do estudo da subjetividade profunda, uma continuidade entre metafísica e as demais áreas do conhecimento e da produção humana, além de concepções de arte de Belchior, Vandré e o último Mário de Andrade, aponta para a indissociabilidade entre as três esferas e para uma axiomática que responda afirmativamente à pergunta “afinal, a arte deve ou não ser engajada?", mas uma resposta pouco ingênua que desloca a problemática da intenção do artista, entendida classicamente como uma atividade conscientemente dirigida a um fim, para o modo de vida, o caráter profundo do artista, que como que escorreria do seu corpo para essa produção do seu corpo que tem existência enquanto uma extensão do criador, levando nela as marcas indeléveis de sua personalidade. Transcreverei a sinopse do referido filme, retirada do site "Adoro Cinema":

Rory Jansen (Bradley Cooper) é casado com Dora (Zoe Saldana) e trabalha em uma editora de livros. Ele sonha em publicar seu próprio livro, mas a cada nova tentativa se convence mais de que não é capaz de escrever algo realmente bom. Um dia, em uma pequena loja de antiguidades, ele encontra uma pasta com várias folhas amareladas. Rory começa a ler e logo não consegue tirar a história da cabeça. Logo ele resolve transcrevê-la para o computador, palavra por palavra, e a apresenta como se fosse seu livro. O texto é publicado e Rory se torna um sucesso de vendas. Entretanto, tudo muda quando ele conhece um senhor (Jeremy Irons) que lhe conta a verdade por trás do texto encontrado ${ }^{1}$.

\section{DA ONTOLOGIA ESTÉTICA AO RELATIVISMO PROFUNDO NA ARTE}

Em vários momentos da história da humanidade se colocou a interminável questão a respeito do que poderia ser um "bom livro", um "grande texto", "algo realmente bom" único, aureático, e a história do pensamento, em seu curso de desenvolvimento (principalmente após Marx e a crítica historicizante às ideologias) tratou de varrer para longe as grandes formulações teóricas, os grandes sistemas filosóficos, as grandes teorias estéticas que definiam rigorosamente em que consistiam tais coisas segundo um complexo de longo alcance explicativo, desvendando sociologicamente o seu caráter arbitrário que se queria universal e conseguia angariar tal posto porque atuava junto a forças ocultas (interesses de classe, principalmente) que lhe emprestavam poder de autoafirmação e status de conhecimento.

Da busca pela verdade absoluta, passamos à esfera da relatividade mais profunda, não só em relação à obra de arte, mas em qualquer esfera de teorização; da Filosofia à análise estrutural de teorias, encarando-as como o que elas realmente seriam: construções humanas 
inspiradas por idiossincrasias e interesses, desejos e fixações próprias do(s) autor(es), que se pretendem absolutamente verdadeiras em seu conteúdo mas não resistem à análise rigorosa da linguagem. Em toda formulação teórica já tornou-se praxe buscarmos os pressupostos subjetivos que são tomados como princípios, inquestionados e inquestionáveis, em que se assentam firmes todo o resto dos edifícios de pensamento, para questioná-los numa regressão ao infinito.

$\mathrm{Na}$ arte as vanguardas fizeram a crítica permanente das pretensões absolutistas de definição do que seria "arte"; se insurgiram contra a tradição e as formas de poder que cristalizavam certos procedimentos e práticas históricas em "verdadeiras e corretas formas" atemporais de proceder artisticamente. Na política, ganharam força as tendências anarquistas entre os jovens. Não restou um único paradigma em pé, tudo parece ter sido colocado em dúvida, inclusive o próprio marxismo (evidentemente, nos setores mais intelectualizados da sociedade - se bem que essa tendência geral podemos encontrar também, ainda que diminuta, em muitos hábitos das ditas "pessoas comuns"). Dos escombros, parecia ressurgir (e as teorizações de Sartre e Groys sobre a arte e política parecem ser um indício disso) novas tendências universalizantes, de quando em quando - muito embora já não gozassem do mesmo alarido de certeza; sempre desconfiados reagimos ceticamente a essas empreitadas. A verdade possível, que se eleva firme, ainda que tímida, no horizonte, e parece poder impor-se com algum grau de convicção é agora uma verdade reduzida em conteúdo, um resíduo de teoria (como bem aponta o excelente conceito de "universalismo fraco" desenvolvido por Groys a partir das leituras de Agamben) que exatamente pelo seu caráter reduzido, poderia resistir aos ataques redutores e exigir a sua aceitação universal, o seu caráter axiomático e definitivo.

A catástrofe geral e perpétua do mundo natural e humano (do meio ambiente e das instituições sociais), entretanto, ainda exige um programa universal, alicerçado sobre um "dever ser" que possa unir todas as alas indiferentes e desesperançosas da sociedade, bem como as dissonantes fragmentações que não podem encontrar consenso, no interior de um mesmo afã humanitário, rumo à mudança urgente e planejada. Necessita-se fundar uma certeza e consenso político, portanto. Em Groys e Sartre, como já mencionado, podemos encontrar boas pistas de um caminho a trilhar nesse sentido. Planos políticos potenciais (e é bem conhecida a teorização de viés sartreana sobre a arte em geral - e a literatura em particular - e sua utilidade revolucionária); mas aqui quero propor um outro. E para fazê-lo, passaremos por três temas clássicos da teoria literária ("escrita e cura", "escrita e amor" e "escrever o luto"), 
essencialmente; um texto (“Literatura e ética - Diana Klinger”), fundamentalmente, nos sugeriu a parte teórica, enquanto quase todos os livros escolhidos e citados na bibliografia parecem servir de exemplos ilustrativos convenientes, dados empíricos corroboradores, caso se queira, do que temos a dizer. Como, no entanto, devemos escolher apenas um para figurar como núcleo duro deste exíguo trabalho, elenque-se "escrita e amor" para esse fim, uma vez que aqui pretendemos falar de amor, em duas formas específicas, tal como identificadas por Freud em "O mal estar na civilização": o amor objetal e o amor universal, que Freud acredita não ter concretude ontológica (Cf. FREUD, 2012, capt. 1).

Para expor tal hipótese e sugerir que ainda é possível pensar em uma definição universal do "grande texto" irei ancorar-me em Bergson, da mesma forma que a Diana foi buscar em Spinoza inspiração para a sua reflexão.

\section{BERGSON E A RECUPERAÇÃO DA BASE ONTOLÓGICA DA EXISTÊNCIA}

Bergson é um autor que defende e pretende demonstrar a existência concreta do amor universal, em "As duas fontes da moral e da religião", principalmente, amparado em toda uma ontologia metafísica. Em uma proposta fenomenológica radical, o contato com a coisa em si, com a realidade última, se daria em uma experiência de alargamento dos sentidos próprias do artista, que percebe por intuição. Nessa chave de leitura e teorização literária, as questões formais do texto, o domínio das técnicas do "fazer artístico" só são importantes na medida em que oferecem recursos para facilitar o reconhecimento do leitor e fixar a sua atenção no texto, tornando-o mais fluído, menos rígido, buscando fugir a todo momento da "sensação de artificialidade" em que toda linguagem prende o sentimento; fazê-lo ver e sentir o que se pretende que veja e sinta com mais intensidade no texto é uma questão natural para o artista, que sequer deve pensar e calcular muito o procedimento visto que é animado de dentro por uma espécie de impulso criador - que se confunde com o Elã Vital, estofo do real no bergsonismo. Nesse sentido parece haver certas técnicas cujo domínio pode ser benéfico ao grande autor, mas não nos parece fundamental que as domine na extensão da especialização completa, nem o mero domínio de todas as técnicas bastaria para formar o grande artista (a noção de sublime tal como aparece no "Tratado do sublime" de Longino será resgatada aqui sob uma nova perspectiva). Importa para a "obra de arte sublime", "grandiosa", mais que tudo, esse impulso que a perpassa, que inunda as letras e dá vida às palavras. Esse impulso que a Diana percebeu, e que nós 
mesmos, vez ou outra, constatamos nas criações humanas. As dores e amores pungentes, profundos, experienciados realmente ou por recurso a uma capacidade empática de abstração, fornecem o melhor material à literatura. Esse impulso pode ser de dois tipos: altruísta ou egoísta. Se provém de uma experiência empática, com Sartre reivindicaremos o potencial democrático da escrita, pedagógico. E retornaremos a propor o projeto romântico da educação sentimental. Se não o for, será um modo egoísta de terapia. O que é usar a escrita como psicanálise se não usá-la sem visar um fim político, mas pessoal? Assim podemos imaginar graus de sublimidade da arte e da escrita. Queremos propor que há uma espécie de sentimento que, se puder transbordar do espírito ao texto e encontrar a forma fluída de expressão que o comunique aos demais, atingirá a maior altura possível.

Tanta metafísica não poderia passar sem Spinoza. Bergson é um filósofo do século XX que foi também profundamente influenciado por Spinoza; considerado o pai da Nova Metafísica, teria feito com que esta ressurgisse em novas bases, após os ataques kantianos, retirando-a dos céus e fazendo rastejar sobre a terra; negou a transcendência para fundar uma metafísica imanente. De maneira rasa e superficial, farei uma exposição geral do que isso significa para os nossos propósitos. É sabido o quanto a noção de uma metafísica transcendente é necessária à toda tentativa axiológica. Platão é o exemplo clássico que determinou a visão cristã de mundo: se houver uma Verdade, ela deve estar em um "outro lugar" que não aqui, no mundo terreno, já que tudo o que aqui está e que pode ser captado por nossos sentidos esvai-se, se corrompe e não dura. A Verdade, ao contrário, deve ser eterna, incorruptível, imutável, logo, deve estar "além da física (physis)". Esse "mundo do além" só poderia ser conhecido pelo pensamento, qualidade humana que sempre tem causado espanto, porque guarda uma peculiaridade eternamente curiosa, de ser dotado de um "espaço interno" em que não estão dispostos quaisquer objetos físicos, e poder formular logicamente raciocínios completos, dispor ali de várias maneiras, os dados da experiência, perscrutar o mundo sem mover um só dedo. Kant (e depois os Positivistas Lógicos, e o próprio aperfeiçoamento das ciências empíricas) mostrou-nos como essa noção de metafísica está fadada ao solipcismo, à inverificabilidade, já que foge aos sentidos, qualquer proposição a respeito da Verdade universal-metafísica poderia muito bem ser uma mera fantasia arbitrária do pensador. Não haveria critério seguro a partir do qual pudéssemos julgá-la intersubjetivamente, como demanda o ethos científico. Como poderíamos ter certeza de algo se não for pela verificação controlada dos sentidos? Se a 
metafísica se quiser um conhecimento totalmente autônomo com relação aos sentidos, à empiria, deve ser descartada.

Nesse cenário insere-se Bergson, e a sua formulação já não descola a verdade metafísica dos dados do sentido. Volta-se a falar em termos desacreditados, como "espírito", "moral", reabre-se a porta para a axiologia a partir de uma tentativa de dar objetividade ao sentimento humano. Um mandamento moral que antes não podia ser verificado em sua verdade, passa a poder, mas a verificação se dará de maneira peculiar. Podemos estar certos de um mandamento moral e podemos defender a sua universalidade por recurso ao que ele chama de "emoção criadora". Linhas gerais, a emoção criadora é uma espécie de sentimento único que todo ser humano, a princípio, é capaz de experimentar, mas nem todos o farão, efetivamente. Freud (2012) confessa não tê-lo feito: trata-se do “amor universal” que ele, no início de seu "Mal estar na civilização" quer refutar, dizendo nunca tê-lo sentido, mas que supõe, a partir das descrições de terceiros que julgam estarem sob seus efeitos, ser só a volta do homem ao estado primitivo do recém nascido preso na confortável e segura "mônada psíquica" (o que é tão inverificável quanto o "mundo das ideias" platônico, enquanto - ele mesmo concordaria - o amor universal é um sentimento positivo que cada vez mais pessoas no mundo inteiro dizem sentir. Há objetividade dessa experiência; ela parece poder ser verificada intersubjetivamente).

Há um problema grave a discutir em relação ao critério a partir do qual podemos ter certeza de estarmos tomados desse sentimento de fato, e não por qualquer fantasia ou impulso primitivo residual da infância, que seja. Basta saber que, segundo Bergson, a objetividade do sentimento é dada por uma constante de caráter, que todas as pessoas verdadeiramente invadidas por essa emoção apresentariam, a saber, a superação do egoísmo e da preocupação exclusiva com o conforto e bem estar pessoal. Nem preciso dizer que os mártires que a história da humanidade produziu apresentavam a mesma despreocupação consigo mesmo, seu ego ofuscado pela entrega total ao ideal solidário, humanitário e altruísta. O ser moral está pronto para ser um mártir; Bergson o caracterizará como um ser empático ao extremo, capaz de dar a vida ou colocá-la em risco, para garantir a liberdade dos outros homens, atitude que seria contrária à natureza (até Freud concordaria), que nos fez obrigados a sobreviver e perpetuar a espécie. Conservar a vida é o primeiro impulso, o natural do humano. Arriscá-la, por pura e espontânea vontade, é fugir à regra. Claro que muitos o fazem por um ato de loucura, e pode ser realmente complicado distinguir a fronteira da loucura e do amor universal à humanidade e a tudo que tem vida; o amor, ainda que objetal (quando se dirige a apenas um ou alguns objetos

Educação, Psicologia e Interfaces, Volume 3, Número 3, p.192-203, Setembro/Dezembro, 2019.

ISSN: 2594-5343. DOI: https://doi.org/10.37444/issn-2594-5343.v3i3.188 
particulares, excluindo os demais) tem uma força que tem sido caracterizada como uma espécie de loucura, desde tempos imemoriais. Esses homens que amam universalmente queimam por dentro se presenciam qualquer tipo de injustiça. Da boca do Che saia as palavras capazes de estremecer "Se você é capaz de tremer de indignação a cada vez que se comete uma injustiça no mundo, então somos companheiros." Funda-se uma comunidade de espírito quando homens que amam universalmente a humanidade se juntam nesse sentimento que, segundo Bergson, é o próprio Ser uno responsável pela vida em tudo o que cresce, se desenvolve e perece pela ação do tempo. Tempo, consciência, a isso Bergson chama "elã vital", uma espécie de impulso escondido nas profundezas mais ocultas da alma, enterrada na parte inconsciente, esperando que a despertem por ressonância, coberta por tantas camadas de imperativos egocêntricos, de preocupações pessoais com a materialidade da própria vida. Uma dimensão não lógica, diria Bergson (e bem reconhece Freud - e pretende demonstrá-lo - que o indivíduo não ganhará nada, não teria motivo algum para amar a todos indistintamente: há seres humanos que merecem o meu ódio) (FREUD, 2022, p.55- 56). Bergson não lhe tirará a razão. Tratará apenas de introduzir uma distinção: o amor que não somos capazes de dar ao homem que merece nosso ódio faz parte da esfera do "amor objetal", o amor libidinal, caso se queira. O amor universal é pela vida e seu livre curso. Se alguém ou algo está obstruindo a passagem do elã, está negando à vida o seu livre curso, deprimindo o seu movimento de realização perpétua e absoluta, impedindo a sua plenitude, nos colocaremos nas palavras de Che mais uma vez: "Fuzilei torturadores, mas nunca torturei ninguém”.

Desse "queimar", desse ímpeto, desse impulso quero sugerir que deve estar investido o escritor para que possamos chamá-lo Grande. Essa ideia parece inundar o livro da Diana Klinger; em diversos momentos ela discute essa potência. Podemos encontrar essa mesma força inexplicável, esse fulgor nos escritos da M. Duras que lemos em sala; nos escritos de Barthes sobre o seu luto; nos escritos de Jorge Semprún, atravessados pela angústia profunda sofrida no campo de concentração. Enfim, sempre que nos deparamos com uma narrativa que parte de um lugar diferente, parte da carne viva, da dor mais profunda, do sofrimento humano, daquele lugar que quer gritar em nós e que diz respeito a nosso interesse vital, parece ser aí que encontramos a boa literatura. Histórias de amor libidinal profundo, de separações amorosas, cumprem o requisito (ainda que não transcendam a esfera do particular rumo ao amor universal, não podendo experimentar da sua potência coletiva), mas estão tão "batidos" pelo uso reiterado que a reprodução pasteurizante lhes roubou em boa medida a aura, superexplorados que foram pela

Educação, Psicologia e Interfaces, Volume 3, Número 3, p. 192-203, Setembro/Dezembro, 2019. ISSN: 2594-5343. DOI: https://doi.org/10.37444/issn-2594-5343.v3i3.188 
cultura de massa que não pode utilizar-se do outro tipo de amor, o universal, sem negar as bases mesmas nas quais opera e literalmente pedir uma revolução de sentimento e pensamento à humanidade, fechada sobre o próprio umbigo, ou no interior das fronteiras de grupos excludentes e egoístas. Quero sugerir com esse texto que há um tipo de narrativa que se eleva ao mais alto grau, e isso a partir da leitura de Bergson: a solidária, a empática, a engajada com a vida e a humanidade em geral. Essa altura pode ser sentida nos textos de Rousseau a Marx; nos relatos das atitudes de Sócrates e de Jesus. "Acima de tudo procurem sentir no mais profundo de vocês qualquer injustiça cometida contra qualquer pessoa em qualquer parte do mundo. É a mais bela qualidade de um revolucionário": esse era o conselho dado por Che Guevara, muito conveniente também ao homem das letras, que pode ser revolucionário antes do momento da revolução ("Sons, palavras são navalhas”, já dizia Belchior em sua música).

Preparar para o combate, como faziam os discursos dos generais da antiguidade; preparar os espíritos para a batalha não pela sobrevivência, ou por um império, mas pela libertação da humanidade não vista; dar voz a ela (e armas). Aqui ou ali, dar motivos para aguentar firme o estalar do chicote, o fardo do trabalho alienante e forçado, enquanto a libertação real não vem. Fazê-los vencer a matéria pelo espírito, da mesma forma que teorizava Schiller quando tratando do sublime, ainda que seja apenas uma vitória de Pirro, e o corpo padeça. Essa foi também a tarefa da religião, mas enquanto esta promete uma salvação imaginária no além vida, aquela promete uma salvação em vida, e um caminho para construíla. A primeira, Marx já o havia mostrado, é instrumento de dominação e gerenciamento do poder, na medida em que aliena os corpos da luta de classes, única via possível para a libertação. A segunda, constrói a unidade de consciência necessária, a coesão e organização da classe trabalhadora. Nos dizeres de Sartre, a escrita é fundamental enquanto diálogo perpétuo (e portátil), sempre pronto e disponível, para esclarecer as massas. Deve ser sempre renovado o esforço de conscientização e desvendamento do mundo para o leitor.

Nesse amor universal parecia imersa Clarice quando escreveu seu último livro, a todas as Macabéias do mundo, do passado, presente e futuro. Na última entrevista que deu em vida dizia ela não querer mudar nada ${ }^{2}$. Talvez soubesse que não poderia: seu ato isolado terá pouco impacto na estrutura sólida que cria Macabéias eternamente. Muito diferente é a proposta de Sartre para o engajamento literário: deve ser o esforço conjunto e perpétuo de toda a comunidade de escritores, unidos sob um mesmo ideal e programa político, que causará impacto real no mundo, na medida em que os leitores farão crescer a corrente por eles iniciada e

Educação, Psicologia e Interfaces, Volume 3, Número 3, p.192-203, Setembro/Dezembro, 2019.

ISSN: 2594-5343. DOI: https://doi.org/10.37444/issn-2594-5343.v3i3.188 
perpetuá-la. Na linguagem de Bergson, trata-se de contaminar as pessoas com a emoção criadora, com o amor universal. A metáfora do contágio é pertinente: o indivíduo revolucionário não viverá isolado dentro de si mesmo, mas sempre estará buscando meios de intervir no mundo. O próprio Sócrates revolucionário não deixou nada escrito. Preferiu, ao invés de fixálas no papel, colocar as palavras em movimento. A fala obrigaria todos a ouvir; a escrita é menos intrusiva, mais seletiva. Ademais, ainda que seus discursos possam passar de seu caráter abstrato para a mais concreta materialidade na escrita sem perder a força, não há como garantir que sejam bem entendidos por quem lesse, visto que as palavras são incertas. Talvez Platão tenha feito o maior serviço à humanidade ao registrar nem tanto as palavras de Sócrates (impossíveis de precisar se foram as mesmas ou chegaram perto - e tudo indica que não), mas ao registrar em palavras as suas ações, tal como se lembrava delas (e isso me recorda as leituras de Bergson). Bergson tentará deixar claro no já referido livro que toda ação humana (inclusive o ato da escrita) são ações do espírito, que partem dele e só podem expressá-lo. Daí a importância do caráter. Não haverá literatura sublime sem sublimidade de caráter, ao menos não no sentido que tentamos traçar aqui. A vida é uma forma de arte, e o que fazemos com nosso corpo é extensão do que se passa em nossa alma, nossa consciência, nosso elã vital, caso se queira. $\mathrm{O}$ ato moral é imediato: está acessível a todos. $\mathrm{O}$ texto é mediado pela linguagem, e hoje encontra-se acessível a quase todos (ou ao menos potencialmente acessível, visto que raramente é acessado). Escrever é também um ato, e o escritor revolucionário vive a completude da sua vida como tal, inclusive ao escrever. Dessa forma, a escrita se fundiria à vida, e as ambiguidades seriam esclarecidas. De fato, não deviam haver muitos manuscritos circulantes à época de Sócrates, que pudessem tornar presentes os seus discursos ao maior número de pessoas possível. Estes necessitavam ainda das cordas vocais de um ser humano concreto e presente para se fazerem valer. Interviria melhor no mundo em praça pública. Bem diferente é o nosso século das tecnologias da informação e comunicação. Quais serão nossas novas praças públicas? Certamente elas existem nos espaços virtuais da escrita, pelos quais transitam escritores e leitores em massa, todos os dias. Acaso nos falta domínio da língua para expressarmo-nos ou para nos entendermos? Acaso ela é insuficiente? Seríamos forçados a concluir que haverá experiências que estão vedadas ao acesso comum, sendo definitivamente privadas e inescrutáveis, portanto, incomunicáveis? Ou imaginamos que o acesso à leitura continua sendo privilégio de um punhado de pessoas? Com Bergson afirmaremos: faz-se hora de engajarmo-nos. E com isso não quer dizer que precisamos ensinar Marx para todo o mundo,

Educação, Psicologia e Interfaces, Volume 3, Número 3, p. 192-203, Setembro/Dezembro, 2019. ISSN: 2594-5343. DOI: https://doi.org/10.37444/issn-2594-5343.v3i3.188 
ou escrever textos complexos de alcance teórico e técnicas formais esotéricas. Trata-se de transmitir uma experiência simples, a experiência do profundo e do vital, em todos os graus que possamos senti-la, mas tendo em mente a finalidade solidária, altruísta. Da profundidade pessoal, repito, a cultura de massa já se apropriou. Histórias de amor e separação, de perda e luto, de superação pessoal, em tudo isso reconhecemos também um grau de força. Mais profunda será quando se entretecerem dramas conjuntos, injustiças de alcance estrutural e ressonância coletiva na construção do mundo novo, livre da injustiça da exploração do homem pelo homem. Talvez os melhores textos sejam justamente estes que são atravessados por essa força misteriosa, metafísica; essa potência que não pode ser ensinada, aprendida ou prevista. Sublimidade longuiniana.

\section{CONSIDERAÇÕES FINAIS}

Voltemos ao exemplo do filme que abre este texto: os manuscritos do livro encontrados na pasta antiga por Rory causam tamanha fixação nele mesmo e no mundo editorial por tratarse de uma narrativa qualitativamente diferente das demais, e todo o mundo a reconhece como tal. O livro passa a ser considerado excepcional não por que inaugura alguma novidade formal, nem porque a história é muito "original” e surpreendente ou qualquer coisa do tipo. Na verdade, foi escrito por um cabo de exército que sabia se comunicar pela escrita apenas em grau suficiente; sabia escrever para os fins imediatos do dia a dia e de acordo com as regras gerais e normas de sua língua, apenas, sem conhecer os cânones ou dominar as técnicas da tradição. A partir do dia em que Rory, um escritor profissional, publica o livro como se fosse dele e angaria capital cultural, publicar os antigos escritos de sua autoria que haviam sido descartados pelas editoras no passado fica fácil, mas não há ninguém, um só leitor ou crítico, que os iguale na comparação com o texto expropriado em "grandeza" e "profundidade". Tratam-se de forças qualitativamente diferentes. $\mathrm{O}$ filme nos sugere que essa força, essa potência fora do comum, vem da própria experiência de vida do cabo do exército, o autor original que perdeu seus manuscritos depois de escrevê-los. Ele havia, na época, conseguido transportar ao papel de maneira orgânica, fluída, quase imediata, a sua experiência profunda que envolve uma história de amor com fim trágico; fez do texto extensão de si. Em contraste, ao ler alguma frase dita por Che Guevara, estremecemos. Dois tipos de experiência profunda, essenciais ao grande texto; duas qualidades de experiência. Ambas podem ser universalizadas, ambas são capazes de

Educação, Psicologia e Interfaces, Volume 3, Número 3, p.192-203, Setembro/Dezembro, 2019.

ISSN: 2594-5343. DOI: https://doi.org/10.37444/issn-2594-5343.v3i3.188 
penetrar no mais profundo da alma humana, mover as paixões e causar fixação. Mas só em uma o momento predominante é altruísta e solidário, despreocupado consigo mesmo. Por isso só uma delas parte da emoção criadora ou do amor universal.

“Que importa onde a morte nos irá surpreender! Que ela seja bemvinda, desde que nosso grito de guerra seja ouvido, que uma outra mão se estenda para empunhar nossas armas e que outros homens se levantem para entoar cantos fúnebres em meio ao crepitar das metralhadoras e novos gritos de guerra e de vitória!" (Che Guevara - frases retiradas da internet).

\section{Notas de rodapé}

${ }^{1}$ http://www.adorocinema.com/filmes/filme-190358/ (último acesso em 20/10/2019).

${ }^{2}$ https://www.youtube.com/watch?v=ohHP112EVnU (último acesso em 20/10/2019).

\section{REFERÊNCIAS BIBLIOGRÁFICAS}

AMARAL. Aracy A. A emergência da consciência política no meio artístico e Os anos 40 como divisor de águas. In: Arte para que? A preocupação social na arte brasileira, 1930-1970. SP: Studio Nobel, 2003, p. 33-127.

ARISTÓTELES, HORÁCIO, LONGINUS. A poética clássica. São Paulo: Cultrix, 1995.

BARTHES, Roland. Fragmentos de um discurso amoroso. trad. Marcia Valeria Martinez de Aguiar, São Paulo: Martins Fontes, 2003.

BATTEUX, Charles. As belas-artes reduzidas a um mesmo princípio. São Paulo: Imprensa Oficial, 2009.

BERGSON, Henri. A Energia Espiritual. São Paulo: Martins Fontes, 2009.

BERGSON, Henri. A Evolução Criadora. Rio de Janeiro: Zahar Editores, 1979.

BERGSON, Henri. As Duas Fontes da Moral e da Religião. RJ: Zahar Editores, 1978.

BERGSON, Henri. Aulas de Psicologia e de metafísica. São Paulo: Martins Fontes, 2014.

BERGSON, Henri. Ensaio sobre os dados imediatos da consciência. Lisboa: Edições 70, 2008.

BERGSON, Henri. Matéria e Memória. São Paulo: Martins Fontes, 1999.

BERGSON, Henri. O pensamento e o movente: ensaios e conferências. São Paulo: M. F., 2006.

BOURDIEU, Pierre. As regras da arte. São Paulo: Companhia das Letras, 2002. 
BÜRGER, Peter. Teoria da vanguarda. São Paulo: Cosac Naify, 2008.

BURKE, Edmund. Investigação filosófica sobre a origem de nossas ideias do sublime e do belo. Campinas: Papirus, 1993.

DURAS, Marguerite. Escrever, trad. Rubens Figueiredo, Rio de Janeiro: Rocco, 1994.

FOUCAULT, Michel. As palavras e as coisas. São Paulo: Martins Fontes, 2007.

FREUD, Sigmund. O mal-estal na civilização. São Paulo: Companhia das Letras, 2012.

KLINGER, Diana. Literatura e ética: da forma para a força. Rio de Janeiro: Rocco, 2014.

LYOTARD, Jean-François. O inumano: considerações sobre o tempo. Lisboa: Estampa, 1997.

SCHILLER, Friedrich. Do sublime ao trágico. Belo Horizonte: Autêntica, 2011.

SEMPRÚN, Jorge. "El día de la muerte de Primo Levi, La escritura o la vida. Barcelona: Tusquets, 1997.

AS PALAVRAS. Direção de Brian Klugman e Lee Sternthal, Estados Unidos, 2012

\section{Credenciais do autor}

PRATES, João Batista Magalhães. Graduado em Filosofia (UNIFESP); Mestrando em Filosofia (UNIFESP). E-mail: batistaprates1@gmail.com

Endereço para correspondência: João Batista Magalhães Prates. Rua Bento Araújo, 149, Barro Branco. CEP: 02345040, São Paulo/SP. E-mail: batistaprates1@ gmail.com

Como citar este artigo (Formato ABNT): PRATES, João Batista Magalhães. Elementos para uma estética engajada. Educação, Psicologia e Interfaces, v. 3, n.3, p. 192-203, 2019.

Recebido: 27/10/2019.

Aceito: 20/11/2019. 